Jurnal Kesehatan Perintis (Perintis's Health Journal) 7 (1) 2020: 69-74

Contents list available at JKP website

PERINTHSS Jurnal Kesehatan Perintis (Perintis's Health Journal)

Journal homepage: https://jurnal.stikesperintis.ac.id/index.php/JKP

\title{
Kelelahan Pada Anak Dengan Leukemia Limfoblastik Akut Dalam Menjalani Kemoterapi Fase Induksi
}

\section{Andrye Fernandes}

\author{
Sekolah Tinggi IImu Kesehatan Perintis Padang, Sumatera Barat, Indonesia
}

Article Information :

Submission: Apr 30, 2020; Revised: Jul 6, 2020; Accepted: Jul 6, 2020; Available online: Jul 12, 2020

*Corresponding author : andryefernandes@stikesperintis.ac.id

\begin{abstract}
ABSTRAK
Kemoterapi memiliki dampak terjadinya kelelahan pada anak yang menderita leukemia limfoblastik akut. Kelelahan yang dialami anak berdampak pada kehidupan dan mempengaruhi kualitas hidup anak. Penelitian ini bertujuan untuk menggambarkan kelelahan yang terjadi pada anak yang menderita leukemia limfoblastik akut yang menjalani kemoterapi fase induksi. Desain penelitian ini adalah deskriptif analitik dengan pengukuran berulang kelelahan pada anak berumur 7-18 tahun $(n=62)$. Pengambilan data dilakukan selama 7 hari yaitu, satu hari sebelum, lima hari selama, dan satu hari setelah kemoterapi. Hasil analisis data didapatkan bahwa hampir seluruh anak mengalami kelelahan (98\%). Kelelahan terjadi selama menjalani kemoterapi dan terus meningkat hingga hari terakhir kemoterapi. Terjadinya kelelahan juga berlanjut setelah kemoterapi. Kesimpulannya kelelahan yang terjadi pada anak terus meningkat selama dan setelah menjalani kemoterapi. Perlu eksplorasi intervensi untuk mengatasi atau meminimalkan kelelahan yang dialami anak sesuai tahap perkembangannya agar meningkatkan kualitas hidup anak.
\end{abstract}

Kata Kunci: anak usia sekolah-remaja, kemoterapi, kelelahan, leukemia limfoblastik akut

\section{ABSTRACT}

Chemotherapy has an impact of fatigue in children who suffer from acute lymphoblastic leukemia (ALL). Fatigue experienced by children has an impact on life and affects the quality of life of children. This study aimed to describe the fatigue that occurs in children suffer from acute lymphoblastic leukemia $w$ hom undergoing one cycle of induction phase chemotherapy. Using descriptive analytic with repeated measurements to 62 children aged 7-18 years. The data were taken for 7 days, one day before chemotherapy, five days during chemotherapy, and one day after chemotherapy. The results of data analysis found that almost all children experienced fatigue (98\%). Fatigue occurs during chemotherapy and continues to increase until the last day of chemotherapy. The occurrence of fatigue also continues after chemotherapy. In conclusion, fatigue that occurs in children continue to increase during and after undergoing chemotherapy. Exploration of interventions is needed to overcome or minimize fatigue experienced by children according to the stage of development in order to improve the quality of life of children.

Keywords: acute lymphoblastic leukemia, adolescence, chemotherapy, child, fatigue 


\section{PENDAHULUAN}

Leukemia limfoblastik akut (LLA) menjadi jenis penyakit leukemia yang paling banyak terjadi pada anak (American Cancer Society, 2015). Pada tahun 2016 di Amerika diperkirakan muncul 60.140 kasus baru leukemia dan sekitar $75 \%$ nya adalah kasus leukemia limfoblastik akut (American Cancer Society, 2016). Selain itu, di Cina leukemia termasuk kedalam penyakit kanker yang paling banyak terjadi pada anak dan remaja yaitu sekitar 20 - 50 juta anak setiap tahunnya (Wu et al., 2010). Indonesia memiliki sekitar 11.000 kasus kanker anak setiap tahunnya dan sepertiga dari kanker anak adalah leukemia dengan jenis terbanyak adalah LLA (Kementerian Kesehatan RI, 2015).

Pengobatan yang berkembang pada anak dengan LLA mampu membuat anak survive dengan LLA sehingga kelangsungan hidup anak meningkatkan (Ye et al., 2016). Tingginya tingkat kelangsungan hidup disekitar $80 \%$ pada pasien anak dengan leukemia (Yee et al., 2013). Kemoterapi menjadi pengobatan yang paling banyak diberikan tanpa disertai dengan Tindakan pembedahan dan radioterapi (Hockenberry \& Wilson, 2011).

Meningkatnya kelangsungan hidup anak LLA dengan melakukan pengobatan kemoterapi tidak seiring dengan penurunan kejadian efek samping dari pengobatan tersebut. Salah satunya efek samping dari kemoterapi yang palin umum terjadi adalah kelelahan (Hilarius et al., 2011). Kelelahan bermakna sebagai perasaan lelah yang luar biasa berhubungan dengan tingginya tingkat tekanan dan ketidakseimbangan terhadap aktvitas pasien. Kelelahan ini tidak hilang dengan tidur atau beristirahat (Weis, 2011).

Prevalensi kelelahan pada pasien kanker berkisar $59 \%$ sampai $100 \%$ yang tergantung pada status klinik kanker (Weis, 2011). Penelitian lainnya yang dilakukan pada anak usia sekolah di Iran dengan LLA yang menjalani kemoterapi didapatkan peningkatan intensitas kelelahan setelah satu jam menjalani kemoterapi dengan prevalensi kejadian $97 \%$ anak mengalami kelelahan (Bastani et al., 2015). Penelitian fenomenologi yang dilakukan oleh Rahmawaty et al. (2014) mengidentifikasi remaja yang menjalani kemoterapi dan mendapatkan kelelahan menjadi hal yang dirasakan remaja selama menjalani kemoterapi.

Kelelahan dibedakan menjadi sentral dan perifer. Kelelahan sentral berasal dari area otak yang berhubungan dengan suasana hati, emosi dan rangsangan psikologis dan berhubungan dengan peningkatan pelelapasan serotonin. Sedangkan kelelahan perifer berhubungan dengan mekanisme seperti transmisi neuromuskuler dan propagansi impuls, disfungsi reticulum sarkoplasma, dan faktor metabolic lainnya yang mengganggu penyediaan energi dan kontraksi otot (Walter et al., 2015).

Identifikasi dan penanganan terhadap kelelahan yang terjadi pada anak dengan LLA sangat penting dilakukan. Jika gejala ini terjadi dalam waktu lama, maka akan menghambat kemampuan anak beraktivitas secara penuh. Bahkan setelah selesai pengobatan, kelelahan ini akan mengganggu peran serta aktivitas anak yang akan membuat hidup anak lebih bermakna (Hilarius et al., 2011). Selain itu kelelahan akan sangat berdampak terhadap kehidupan dan mempengaruhi kualitas hidup anak (Rahmawaty et al., 2014).

Kelelahan pada anak dengan kanker tidak mudah dibedakan dengan rasa lelah karena aktivitas sehari-hari tanpa evaluasi diagnostik yang cermat (Barsevick et al., 2013). Pasien anak dengan kanker dan keluarga tidak melaporkan kelelahan kepada dokter dan perawat karena mereka mungkin berfikir kelelahan adalah gejala yang biasa muncul karena kemoterapi sehingga mereka harus beradaptasi dan mengurangi harapan mereka kelelahan ini akan hilang atau berkurang (Bastani et al., 2015) Akibatnya kelelahan secara terus menerus diabaikan, kurang ditemukan, dan tidak ditangani khususnya di Indonesia.

Beda penelitian ini dengen penelitian sebelumnya adalah Penelitian ini tidak menggambarkan kelelahan yang terjadi pada anak dalam satu waktu, tapi dalam beberapa waktu yaitu selama kemoterapi fase induksi. Sehingga dapat diketahui kapan kelelahan muncul dan trend peningkatan keparahan kelelahan yang terjadi pada anak. Pentingnya penelitian ini dilakukan untuk mengevaluasi kelelahan 
yang terjadi pada anak setiap hari selama menjalani kemoterapi fase induksi. Karena fase induksi merupakan fase pertama kemoterapi dan memberikan high dose obat kemoterapi (Fernandes, 2019). Apabila tidak diidentifikasi dari awal akan memperburuk kelelahan yang dirasakan anak dan akan berlanjut pada fase-fase kemoterapi selanjutnya. Penelitian ini bertujuan untuk menggambarkan kelelahan yang terjadi pada anak usia 7-18 tahun (usia sekolah dan usia remaja) yang menjalani kemoterapi fase induksi.

\section{METODE PENELITIAN}

Metode yang digunakan dalam penelitian ini adalah deskriptif analitik repeated measure. Melakukan pengukuran atau observasi variabel dalam beberapa waktu. Tempat penelitian di Rumah sakit Umum Arifin Achmad dan Rumah Sakit Ibu dan Anak Eria Bunda Kota Pekanbaru yang dilakukan pada tahun 2017 dengan waktu pengambilan data 3 bulan. Seluruh anak dengan LLA yang menjalani kemoterapi fase induksi menjadi populasi dalam penelitian. Jumlah sampel 62 orang yang didapat dari rumus penghitungan sampel untuk penelitian yang bertujuan mengetahui nilai mean suatu variabel. Sampel terdiri dari anak usia sekolah (7-12 tahun) dan anak usia remaja (13-18 tahun) dengan LLA yang menjalani kemoterapi fase induksi. Sampel disyaratkan belum pernah mendapatkan kemoterapi sebelumnya dan dalam kesadaran penuh. Seluruh responden berpartisipasi penuh dalam penelitian ini dan tidak ada yang drop out. Nonprobability sampling jenis consecutive sampling digunakan dalam teknik pengambilan sampel. Teknik ini dilakukan dengan memilih semua individu yang ditemui dan memenuhi kriteria pemilihan yang telah ditetapkan hingga jumlah sampel yang diinginkan terpenuhi. Kuesioner data demografi (nama, usia, dan jenis kelamin), dan Skala Fatigue Onkologi Anak_Allen (Skala FOA-A) digunakan dalam mengumpulkan data penelitian. Uji validitas dan reablilitas terhadap instrument skala FOA-A didapatkan hasil validity statistics dengan $r$ item 0,509-0,884 dan reliability statistics yaitu 0,948 dengan hasil cronbach's alpha 0,948. Hal ini menunjukkan bahwa instrument ini valid dan reliabel untuk digunakan (Allenidekania, 2009).

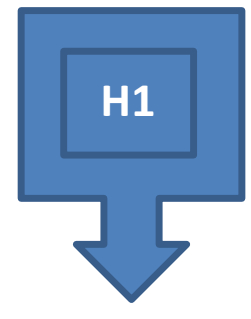

A

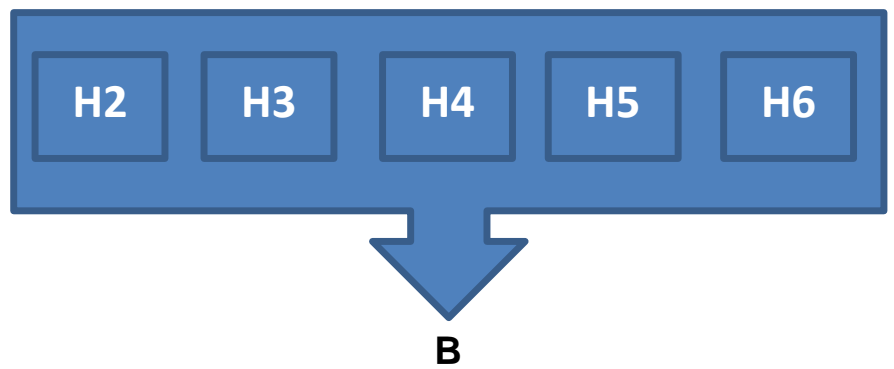

B

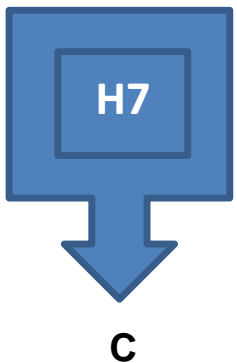

Skema 1. Alur Penelitian
Keterangan:

A : Penilaian kelelahan pada anak satu hari sebelum kemoterapi

B :Penilaian kelelahan pada anak selama mendapatkan obat kemoterapi (skore kelelahan selama lima hari diambil nilai rata-ratanya)

C : Penilaian kelelahan pada anak setelah selesai mendapatkan obat kemoterapi

Instrumen yang digunakan untuk mengukur kelelahan anak adalah Skala Fatigue Onkologi Anak (Skala FOA-A).
Instrumen ini memiliki 10 item pernyataan yang berupa gambaran gejala kelelahan yang dirasakan oleh anak. Pada instrumen, responden akan menjawab seberapa sering merasakan gejala kelelahan. Alternatif jawaban menggunakan 4 poin skala likert, yaitu $0=$ tidak pernah merasakan, 1 =jarang merasakan, 2=sering merasakan, dan $3=$ selalu merasakan. Penilaian akan ditransformasikan kedalam rentang nilai 0 30. Dikatakan mengalami kelelahan bila didapatkan skor kelelahan pada instrumen lebih dari 6. Semakin tinggi total skor, menunjukkan semakin berat kelelahan 
yang dirasakan. Pengambilan data dilakukan selama proses kemoterapi (tujuh hari) yaitu mulai dari satu hari sebelum menjalani kemoterapi, lima hari selama menjalani kemoterapi, dan satu hari setelah kemoterapi selesai diberikan sesuai dengan skema 1.

Dalam pengumpulan data peneliti selalu menerapkan protection from discomfort and harm dengan selalu melihat kondisi pasien. Ketika responden terlihat sangat lelah, peneliti tidak memaksa responden untuk tetap mengisi kuesioner sendiri dan memfasilitasi responden untuk mengisi dengan cara menjawab pertanyaan yang ada dikuesioner secara verbal yang dibacakan peneliti atau orangtua. Data yang sudah didapat diperiksa kembali kelengkapannya bersama responden. Data dimasukkan dan diberi kode. Kemudian diolah kedalam aplikasi pengolahan data untuk dianalisis. Peneliti menggunakan sistem komputerisasi dengan melakukan deskriptif numerik untuk mengolah data. Dalam penelitian ini peneliti memastikan setiap jawaban yang diberikan responden dengan mengsingkronkan jawaban dengan kondisi fisik yang berhubungan dengan kelelahan responden. Sehingga didapatkan hasil yang mewakili kondisi responden

\section{HASIL DAN PEMBAHASAN}

Tabel 1 menunjukkan distribusi responden berdasarkan usia yaitu usia anak sekolah (7-12 tahun) mendominasi usia responden $(72,6 \%)$ dan dari jenis kelamin sebagian besar responden adalah laki-laki (51,6\%). Hasil penelitian ditemukan gambaran rerata skor kelelahan sebelum kemoterapi, selama kemoterapi, dan setelah kemoterapi. Rerata skor mengalami penambahan \pm 6 skor pada anak sekolah dan remaja selama mendapatkan kemoterapi dan setelah mendapatkan kemoterapi. Bila dihitung terjadi peningkatan 11 skor pada anak sekolah dan 12 skor pada anak remaja selama satu siklus kemoterapi. Peningkatan skor kelelahan anak dimulai dari hari ketiga kemoterapi sampai satu hari setelah kemoterapi. Dapat dilihat rerata skor kelelahan pada anak paling tinggi setelah menjalani kemoterapi. Rerata skor kelelahan pada anak tergambar pada (grafik 1)

\section{Tabel 1. Distribusi Responden Berdasarkan Usia, dan Jenis Kelamin}

\begin{tabular}{lcc}
\hline \multicolumn{1}{c}{ Variabel } & (f) & (\%) \\
Usia & & \\
Usia Sekolah & $\mathbf{4 5}$ & $\mathbf{7 2 , 6}$ \\
Usia Remaja & $\mathbf{1 7}$ & $\mathbf{2 7 , 4}$ \\
Total & 62 & 100,0 \\
Jenis Kelamin & & \\
Laki-Laki & $\mathbf{3 2}$ & $\mathbf{5 1 , 6}$ \\
Perempuan & $\mathbf{3 0}$ & $\mathbf{4 8 , 4}$ \\
Total & 62 & 100,0 \\
\hline
\end{tabular}

Tabel 2 menunjukkan rerata skor kelelahan pada anak usia remaja $(18,7)$ lebih tinggi dari rerata skor anak usia sekolah $(11,6)$ yang sedang menjalani kemoterapi. Prevalensi terjadinya kelelahan pada anak yang menjalani kemoterapi adalah $98 \%$ dari seluruh sampel.

Prevalensi anak yang mengalami kelelahan $98 \%$ dengan didapatkan rerata skor kelelahan yang dialami anak lebih dari 6. Hal ini menunjukkan bahwa anak yang menjalani kemoterapi mengalami kelelahan. Penelitian ini sesuai dengan penelitian yang dilakukan Yılmaz, Gerçeker and Muslu, (2016) yang menyebutkan rerata kelelahan yang dialami anak yang menjalani pengobatan kemoterapi menunjukkan terjadinya kelelahan. Sekitar $40 \%$ pasien kanker yang mendapatkan kemoterapi mengalami kelelahan (Bastani et al., 2015). Sesuai dengan hasil penelitian ini, pasien anak yang menjalani kemoterapi didapatkan merasakan kelelahan. Gambaran skor kelelahan yang dialami responden usia sekolah dan remaja yang menjalani kemoterapi mengalami peningkatan setiap harinya. Skor kelelahan selama dan setelah kemoterapi lebih tinggi dari skor kelelahan sebelum mendapatkan kemoterapi.

Peningkatan skor kelelahan menunjukkan semakin berat kelelahan responden selama menjalani kemoterapi. Anak usia remaja memiliki skor kelelahan lebih tinggi dari usia sekolah, dapat disimpulkan bahwa kelelahan yang dirasakan anak usia remaja lebih berat dari pada anak usia sekolah Pada hari setelah mendapatkan kemoterapi $(\mathrm{H} 7)$ masih terjadi peningkatan skor kelelahan pada anak usia sekolah dan remaja. Tingkat kelelahan 


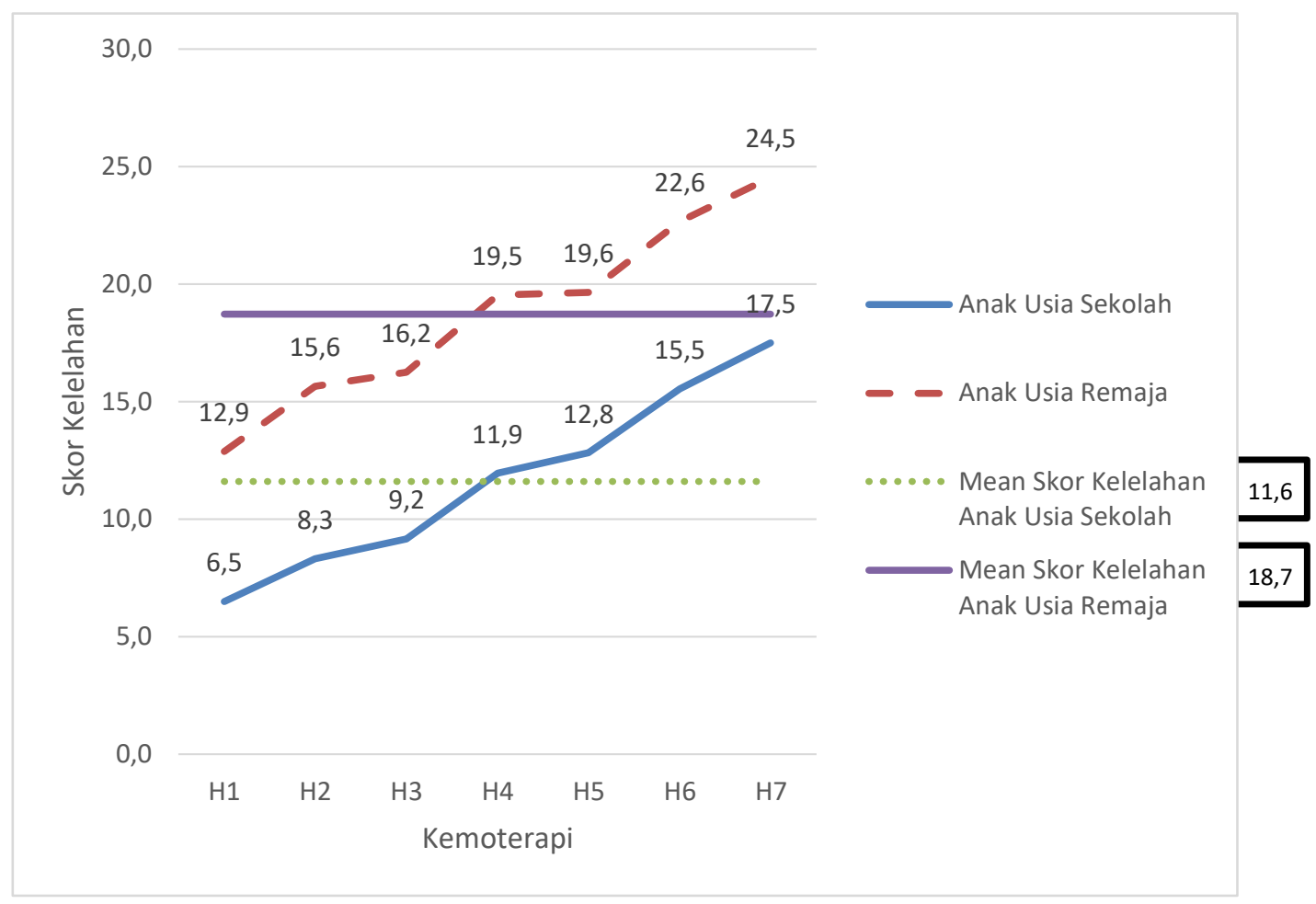

\section{Grafik 1. Rerata Skor Kelelahan Anak Selama Tujuh Hari Mendapatkan Kemoterapi}

berfluktuasi selama menjalani kemoterapi. Kelelahan akan meningkat selama mendapatkan kemoterapi dan akan terus meningkat setelah mendapatkan kemoterapi (Erickson et al., 2010; Yasin and Al-hamad, 2015). Rerata skor kelelahan selama kemoterapi adalah 3,76 dan setelah satu minggu mendapatkan kemoterapi meningkat menjadi 5,71. Dengan demikian skor kelelahan meningkat sebesar $52 \%$. Kelelahan menjadi fenomena kompleks yang secara signifikan dapat mempengaruhi kualitas hidup anak selama perawatan, setelah perawatan dan pada fase bertahan hidup (Kestler and Lobiondowood, 2012).

Tabel 2. Rerata Skor Kelelahan Selama Menjalani Kemoterapi

\begin{tabular}{ccccccc}
\hline Variabel & $\mathbf{n}$ & Mean & SD & $\begin{array}{c}\text { Min- } \\
\text { mak }\end{array}$ & 95\% Cl & Prevalensi \\
Kelelahan & & & & & & \\
Usia Sekolah & 45 & 11,6 & 3,82 & $0-19$ & $10,5-12,8$ & 98 \\
Usia Remaja & 17 & 18,7 & 3,76 & $6,8-23,2$ & $16,7-20,6$ & \\
\hline
\end{tabular}

\section{KESIMPULAN}

Dari penelitian yang dilakukan terjadi kelelahan pada anak dengan leukemia limfoblastik akut yang menjalani kemoterapi fase induksi. Hampir seluruh anak dan remaja mengalami kelelahan dalam mejalani kemoterapi (98\%). Kelelahan terjadi selama menjalani kemoterapi dan terus meningkat hingga hari terakhir kemoterapi. Terjadinya kelelahan juga berlanjut setelah kemoterapi selesai karena didapatkan adanya peningkatan skor kelelahan pada anak setelah menjalani kemoterapi. Perlu eksplorasi intervensi untuk mengatasi atau meminimalkan kelelahan yang dialami anak sesuai tahap perkembangannya agar meningkatkan kualitas hidup anak.

\section{REFERENSI}

Allenidekania. (2009). Pengembangan Alat Ukur Kelelahan dan Masalah Tidur pada anak dengan kanker. Tidak dipublikasikan. 
American Cancer Society (2015) Childhood leukemia. Available at: http://www.cancer.org/acs/groups/cid/d ocuments/webcontent/003095pdf.

American Cancer Society (2016) Cancer facts \& figures 2016. Available at: http://www.cancer.org/acs/groups/cont ent/@research/documents/document/ acspc-047079.pdf.

Barsevick, A. M. et al. (2013) 'Recommendations for High-Priority Research on Cancer-Related Fatigue in Children and Adults', JNCl: Journal of the National Cancer Institute, 5(19). doi: 10.1093/jnci/djt242.

Bastani, F. et al. (2015) 'The effect of acupressure on cancer-related fatigue among school-aged children with acute lymphoblastic leukemia', Irian Journal Of Nursing And Midwifery Research 20(5), pp. 545-552. doi: 10.4103/17359066.164508 .

Erickson, J. M. et al. (2010) 'Patterns of fatigue in adolescents receiving chemotherapy.', Oncology nursing forum, 37(4), pp. 444-455. doi: 10.1188/10.ONF.444-455.

Fernandes, A. (2019) 'Masalah tidur anak dengan leukemia limfoblastik akut dalam menjalani kemoterapi fase induksi', Jurnal Kesehatan Perintis (Perintis's Health Journal), 6(1 SEArticles). doi: 10.33653/jkp.v6i1.244.

Hilarius, D. L. et al. (2011) 'Cancer-related fatigue : clinical practice versus practice guidelines', Supportive Care in Cancer pp. 531-538. doi: 10.1007/s00520-010-0848-3.

Hockenberry, M. J. \& Wilson, D. (2011) Wong's nursing care of infants and children. 9th edn. St.Louis: ElsevierMosby.

Kementerian Kesehatan RI (2015) 'Infodatin Pusat Data dan Informasi Kementerian Kesehatan Rl'. Available at:

http://www.depkes.go.id/resources/dow nload/pusdatin/infodatin/infodatinkanke r.pdf.

Kestler, S. A. and Lobiondo-wood, G. (2012) 'Review of Symptom Experiences in Children and Adolescents With Cancer', Cancer Nurs. 35(2), pp. 31-49. doi:
10.1097/NCC.0b013e3182207a2a.

Rahmawaty, F. et al. (2014) 'Sleep Disturbances and Fatigue in Adolescents with Cancer Receiving Chemotherapy', Makara Journal of Health Research 18(2), pp. 87-94. doi: 10.7454/msk.v18i2.4073.

Walter, L. M. et al. (2015) 'Sleep and fatigue in pediatric oncology: A review of the literature', Sleep Medicine Reviews. Elsevier Ltd, 24, pp. 71-82. doi: 10.1016/j.smrv.2015.01.001.

Weis, J. (2011) 'Cancer-related fatigue: prevalence, assessment and treatment strategies', Expert Review of Pharmacoeconomics \& Outcomes Research. Taylor \& Francis, 11(4), pp. 441-446. doi: 10.1586/erp.11.44.

$\mathrm{Wu}, \mathrm{M}$. et al. (2010) The experiences of cancer-related fatigue among Chinese children with leukaemia: $A$ phenomenological study', 'International Journal of Nursing Studies 47, pp. 4959. doi: 10.1016/j.ijnurstu.2009.05.026.

Yasin, Y. M. and Al-hamad, A. (2015) 'Anxiety and depression as key determinants of cancer related fatigue among patients receiving chemotherapy', European Scientific Journal 11(33), pp. 39-53.

Ye, Q. et al. (2016) 'ScienceDirect Reliability and validity of the Chinese version of the PedsQL Multidimensional Fatigue Scale in children with acute leukemia', International Journal of Nursing Sciences. Elsevier Ltd, 3(2), pp. 146152. doi: 10.1016/j.jnss.2016.04.001.

Yee, S. et al. (2013) 'Physical activity of pediatric patients with acute leukemia undergoing induction or consolidation chemotherapy', Leukemia Research. Elsevier Ltd, 37(1), pp. 14-20. doi: 10.1016/j.leukres.2012.09.005.

Yılmaz, H. B., Gerçeker, G. Ö. and Muslu, G. K. (2016) 'Evaluating the cancer related fatigue by children, mothers, and nurses in Turkish pediatric oncology patients.', European journal of oncology nursing: the official journal of European Oncology Nursing Society. Scotland, 23, pp. 66-71. doi: 10.1016/j.ejon.2016.05.002. 